\title{
Incomplete excision of basal cell carcinoma (BCC) in the head and neck region: to wait, or not to wait?
}

\author{
Jakub Miszczyk, Michał Charytonowicz, Tomasz Dębski, Bartłomiej Noszczyk \\ Department of Plastic Surgery, Medical Centre for Postgraduate Education, Professor W. Orlowski Memorial Hospital, Warsaw, Poland \\ Adv Dermatol Allergol 2017; XXXIV (6): 607-611 \\ DOI: https://doi.org/10.5114/ada.2017.72467
}

\begin{abstract}
Introduction: Recurrence rates for incompletely excised basal cell carcinoma (BCC) vary widely in the literature. Clinical observation is a commonly accepted method of follow up, however such management of these lesions still remains controversial.

Aim: To evaluate the rate and factors associated with the recurrence of BCC of the head and neck region after incomplete excision.

Material and methods: Medical records of 135 patients with 156 incompletely excised BCCs of the head and neck region were analyzed retrospectively. The primary outcome was the rate of recurrence. Additionally, a correlation of recurrence to clinical and morphological factors was analyzed.

Results: Recurrence occurred in 72 (46\%) lesions. The mean interval to recurrence was 20 months. In each category of factors, the highest relative risk of recurrence was correlated to: location on the scalp -2.27 , diameter over $2 \mathrm{~cm}-1.21$, nodular clinical form -1.29 , morpheaform histopathological type -1.67 , recurrent lesion -1.88 , irradicality of excision in the lateral margin -1.24 and closure of the skin defect with the split-thickness skin graft -1.42 relative risk.

Conclusions: Observation is an acceptable management option as less than a half of incompletely excised BCCS recurred and needed further treatment. As $85 \%$ of recurrences occur within 3 years after operation, clinical observation should be particularly careful during this period, however long-term recurrence should not be underestimated.
\end{abstract}

Key words: basal cell carcinoma, incomplete excision, recurrence rate.

\section{Introduction}

Skin cancer is the most common form of human malignancies and it accounts for almost $1 / 3$ of all detectable neoplasms [1]. Out of skin cancers, basal cell carcinoma (BCC) originating from the basal cell layer of the epidermis is the most common one and constitutes over $75 \%$ of lesions [2]. It is usually located in the head and neck region - in over $80 \%$ of cases [3].

Surgery is currently the gold standard for BCC treatment [2]. Despite numerous advantages of surgical excision, some lesions are still being excised incompletely. Incomplete excision of BCC is defined as presence of tumor identified by the histopathologist at the surgical edge or at a distance of less than $0.5 \mathrm{~mm}$ from it (one high-power field at 400 times magnification) [4]. On average, $4.7-7 \%$ of lesions are being excised incompletely $[5,6]$. These numbers prove that a problem is huge and the necessity to improve the procedure completeness is undeniable, however management following incomplete excision raises many controversies [7, 8].

Careful follow-up is currently the most popular method of managing such lesions, in front of re-excision or radiotherapy, performed immediately after the histopathological diagnosis of irradicality [2]. Supporters of follow-up base their opinions on studies proving that recurrent disease will occur only in $30-67 \%$ of cases out of all incompletely excised lesions [9], so even up to $2 / 3$ of tumor tissue left in the skin will not recur. In addition, prospective studies where incompletely excised BCCS were re-excised showed the presence of tumor tissue only in $45-54 \%$ of specimens $[5,10]$. It means that in about half of cases, the tumor tissue, which was left in the skin, undergoes regression, possibly with the help of the immune system [11].

Address for correspondence: Jakub Miszczyk MD, Department of Plastic Surgery, Medical Centre for Postgraduate Education, Professor W. Orlowski Memorial Hospital, 231 Czerniakowska St, 00-416 Warsaw, Poland, phone: +48 668240931 ,

e-mail: jakubmiszczyk@gmail.com

Received: 11.08.2016, accepted: 8.11.2016. 


\section{Aim}

We have decided to evaluate the recurrence rate of incompletely excised BCCs of the head and neck region in our department in 2000-2010 and to determine if there are any clinical or morphological features which may help predicting the recurrence and adjusting the followup schedule.

\section{Material and methods}

A hospital-based, retrospective, cohort study design was used to recruit patients. We searched through medical records of all patients with incompletely excised BCC of the head and neck region operated in the Department of Plastic Surgery of Postgraduate Medical Education Centre, Professor W. Orlowski Memorial Hospital in Warsaw between January 2000 and December 2010. The primary outcome was the rate of recurrence. Recurrence was defined as a clinically diagnosed new focus of tumor in a scar or in its vicinity, confirmed histopathologically after excision.

Additionally, risk factors and relevant aspects of clinical examination were analyzed to assess which factors (cancer location, diameter, clinical form, histopathological type, primary or recurrent character of the lesion, site of irradicality and method of skin defect closure) increase the relative risk of recurrence of $B C C$ in the head and neck region after incomplete excision. All data in each category of factors were then transcribed by using binary variables, as follows for example in the category 'site of irradicality' - irradicality in the lateral margin: yes $=1$ (85 cases), no $=0$ (71 cases); irradicality in the deep margin: yes $=1$ (61 cases), no = 0 (95 cases); irradicality in both margins: yes $=1$ (10 cases), no $=0$ (146 cases). Relative risks were then calculated for each individual risk factor in every category by using the $\chi^{2}$ test. For each relative risk calculated, a 95\% confidence interval was given and a $p$-value was calculated using the Fisher exact test. Although the design of the study is retrospective, we used the relative risk instead of the odds ratio, as our study fully follows a cohort study design, and not a casecontrol one.

\section{Results}

A total of 156 cases of incompletely excised BCC in the head and neck region among 135 patients with a mean age of $71 \pm 12$ years were identified using surgical records, enrolled in the cohort and then checked for presence or absence of recurrence. The mean follow-up period was $25 \pm 20$ months (median: 22 months), ranging from 1 to 110 months.

Recurrence occurred in 72 lesions, resulting in a 46\% recurrence rate, among 54 patients. The mean age of patients with recurrence was $70 \pm 14$ years vs. $71 \pm 11$ years in the group with no recurrence, so age of the patient does not seem to be a risk factor for recurrence in our series. The mean interval to recurrence was $20 \pm 15$ months (median: 14 months) ranging from 1 to 73 months. $42 \%$ of recurrences occurred within one year after the incomplete excision, $26 \%$ during the $2^{\text {nd }}$ year, $17 \%$ during the $3^{\text {rd }}$ year, $7 \%$ during the $4^{\text {th }}$ and $5 \%$ during the $5^{\text {th }}$ year. In 2 cases, recurrence occurred after a period longer than 5 years. It means that as much as $85 \%$ of recurrences occurred within 3 years after the incomplete excision.

We found an association of recurrence with clinical and morphological factors presented below.

Concerning the location of the lesion, the site with the highest relative risk of developing the recurrence was the scalp with $100 \%$ recurrence rate and relative risk of 2.27 , in front of the cheek - relative risk of 1.34, forehead -1.1 , ear -1.09 and periorbital region -1.07. Location on the scalp was statistically a very significant risk factor (Table 1).

Surprisingly, the highest relative risk of recurrence was not observed in lesions with the largest dimensions, as 1.21 relative risk value was associated with a diameter between 2 and $5 \mathrm{~cm}$ ( $p=0.28$; 95\% Cl: 0.84-1.74). The relative risk of recurrence for lesions with a diameter $<2 \mathrm{~cm}$ and $>5 \mathrm{~cm}$ was less than 1 .

Concerning the macroscopic clinical (not histopathological) appearance - nodular and elevated clinical forms were associated with the highest relative risk of developing the recurrence (Table 2).

The histopathological type of an incompletely excised $\mathrm{BCC}$ is one of the most important factors determining the recurrence rate. In our study, we found a well-established relation between the incompletely excised BCC morpheaform histopathological type and recurrence - relative risk of 1.67, in front of adnexogenes -1.34 , infiltrative -1.33 , nodularis and superficial - both 1.09. Morpheaform histopathological type was statistically a very significant risk factor for recurrence (Table 3).

Recurrence occurred in $76 \%$ of treated recurrences (lesions which recurred after the previous incomplete excision and afterwards were excised incompletely) vs. $40 \%$ of primary lesions, so the risk of another recurrence (second, third, etc.) is almost 2 times higher ( $R R=1.88$; $p=0.001 ; 95 \% \mathrm{Cl}: 1.27-2.37)$ than in the case of a primary lesion (than the first recurrence). Furthermore, it is thought that some incompletely excised lesions recur in a more aggressive growth pattern, especially in the central face [12].

Relating to the margins involved, we found an association of a positive lateral margin with a higher risk of recurrence $(R R=1.24 ; p=0.22 ; 95 \% \mathrm{Cl}$ : 0.86-1.82). Surprisingly, the involvement of multiple margins was statistically not a significant risk factor $(R R=1.09$; $p=0.8 ; 95 \% \mathrm{Cl}: 0.43-1.81$ ).

One more important aspect is the technique of skin closure after excision. The relative risk of 1.42 was observed after closure with a split thickness skin graft 
Table 1. Association of BCC location with recurrence rate

\begin{tabular}{|c|c|c|c|c|c|c|}
\hline Location & $\begin{array}{l}\text { Number } \\
\text { of cases }\end{array}$ & $\begin{array}{c}\text { Number } \\
\text { of recurrences }\end{array}$ & $\begin{array}{l}\text { Recurrence } \\
\text { rate (\%) }\end{array}$ & Relative risk & $P$-value & $\begin{array}{c}95 \% \text { confidence } \\
\text { interval }\end{array}$ \\
\hline Scalp & 6 & 6 & 100 & 2.27 & 0.007 & $1.14-2.27$ \\
\hline Cheek & 22 & 13 & 59 & 1.34 & 0.19 & $0.80-1.90$ \\
\hline Forehead & 24 & 12 & 50 & 1.10 & 0.68 & $0.63-1.65$ \\
\hline Ear & 12 & 6 & 50 & 1.09 & 0.78 & $0.47-1.77$ \\
\hline Periorbital & 36 & 17 & 47 & 1.07 & 0.75 & $0.66-1.58$ \\
\hline Perioral & 20 & 7 & 35 & $<1$ & & \\
\hline Nose & 36 & 11 & 31 & $<1$ & & \\
\hline All & 156 & 72 & 46 & & & \\
\hline
\end{tabular}

Table 2. Association of BCC clinical form with recurrence rate

\begin{tabular}{|c|c|c|c|c|c|c|}
\hline $\begin{array}{l}\text { Clinical form } \\
\text { (macroscopic) }\end{array}$ & $\begin{array}{l}\text { Number } \\
\text { of cases }\end{array}$ & $\begin{array}{c}\text { Number } \\
\text { of recurrences }\end{array}$ & $\begin{array}{l}\text { Recurrence } \\
\text { rate (\%) }\end{array}$ & $\begin{array}{l}\text { Relative } \\
\text { risk }\end{array}$ & $P$-value & $\begin{array}{c}95 \% \text { confidence } \\
\text { interval }\end{array}$ \\
\hline Nodular & 34 & 19 & 56 & 1.29 & 0.20 & $0.83-1.82$ \\
\hline Elevated & 22 & 12 & 55 & 1.22 & 0.39 & $0.70-1.78$ \\
\hline Cicatricial & 11 & 5 & 45 & $<1$ & & \\
\hline Ulcerated & 79 & 33 & 42 & $<1$ & & \\
\hline Unknown & 10 & 3 & - & - & & \\
\hline All & 156 & 72 & 46 & & & \\
\hline
\end{tabular}

Table 3. Association of BCC histopathological type with recurrence rate

\begin{tabular}{|c|c|c|c|c|c|c|}
\hline $\begin{array}{l}\text { Histopathological } \\
\text { type }\end{array}$ & $\begin{array}{l}\text { Number } \\
\text { of cases }\end{array}$ & $\begin{array}{c}\text { Number } \\
\text { of recurrences }\end{array}$ & $\begin{array}{l}\text { Recurrence } \\
\text { rate (\%) }\end{array}$ & Relative risk & $P$-value & $\begin{array}{c}95 \% \text { confidence } \\
\text { interval }\end{array}$ \\
\hline Morpheaform & 26 & 18 & 69 & 1.67 & 0.01 & $1.10-2.19$ \\
\hline Adnexogenes & 15 & 9 & 60 & 1.34 & 0.26 & $0.71-1.94$ \\
\hline Infiltrative & 10 & 6 & 60 & 1.33 & 0.36 & $0.59-1.98$ \\
\hline Nodularis & 16 & 8 & 50 & 1.09 & 0.75 & $0.54-1.72$ \\
\hline Superficial & 4 & 2 & 50 & 1.09 & 0.88 & $0.20-2.02$ \\
\hline Keratoticum & 5 & 2 & 40 & $<1$ & & \\
\hline Exulcerans & 70 & 24 & 34 & $<1$ & & \\
\hline Unknown & 10 & 3 & - & - & & \\
\hline All & 156 & 72 & 46 & & & \\
\hline
\end{tabular}

(Table 4). However, it is consensual that the method of closure does not influence the recurrence, yet closure using split thickness skin grafts improve the recurrence diagnosis, as we observed also in our study. The median interval to recurrence in the group treated with a split thickness skin graft was 12 months vs. 16 months in the group treated with other closure methods.

\section{Discussion}

Our results, with $46 \%$ recurrence rate, are similar to those presented in the literature [9]. The time from incomplete excision to recurrence also corresponds to outcomes presented by other authors. For example in a study by Marcil and Stern [13], as many as $82 \%$ of recurrences occurred in the first 5 years, and about 30\% of cases were diagnosed in the first year of observation, $20 \%$ in the second and 16\% in the third year.

The morpheaform histopathological type, which was correlated to the highest relative risk of developing the recurrence in our series, is said to be one of the most aggressive and can infiltrate tissues even up to the width of $7 \mathrm{~mm}$ beyond macroscopic borders of a lesion [14]. Moreover it is sometimes difficult to diagnose the recur- 
Table 4. Association of skin defect closure method with recurrence rate

\begin{tabular}{lcccccc}
\hline Method of closure & $\begin{array}{c}\text { Number } \\
\text { of cases }\end{array}$ & $\begin{array}{c}\text { Number } \\
\text { of recurrences }\end{array}$ & $\begin{array}{c}\text { Recurrence } \\
\text { rate (\%) }\end{array}$ & $\begin{array}{c}\text { Relative } \\
\text { risk }\end{array}$ & $\begin{array}{c}P \text {-value } \\
\text { 95\% confidence } \\
\text { interval }\end{array}$ \\
\hline Split-thickness skin graft & 37 & 22 & 59 & 1.42 & 0.063 & $0.94-1.95$ \\
\hline Local skin flap & 109 & 48 & 44 & $<1$ & & \\
\hline Full-thickness skin graft & 5 & 2 & 40 & $<1$ & & \\
\hline Direct closure & 5 & 0 & 0 & $<1$ & \\
\hline All & 156 & 72 & 46 & & \\
\hline
\end{tabular}

rence in cases of the morpheaform type, as it quite often resembles the cicatricial tissue after primary excision.

Our study also emphasized the difficulty of surgical treatment of recurrent lesions, what results in a considerably lower success rate also mentioned by other authors [15]. In the study by Silverman et al. [16], a risk of another recurrence was 50\% higher than in the case of a primary lesion, what corresponds to the relative risk of 1.88 obtained in our study.

What might be quite surprising - concerning the location of the lesion - all of 6 incompletely excised BCCs on the scalp recurred in our series. It is hard to find a common factor in these 6 cases, except for the fact that none of the lesions infiltrated bone, nor even epicranial aponeurosis in histopathological examination. The rest of describing factors was very diverse in this series. The diameter of scalp lesions ranged from $12 \mathrm{~mm}$ up to $80 \mathrm{~mm}$, irradicality occurred in both - lateral and deep margins. Three of the lesions were characterized by an aggressive histopathological subtype and 3 by a nonaggressive subtype. Concerning the patients with the scalp BCC recurrence -2 of them were males and 4 were females, with the age ranging from 63 years to 86 years. Recurrence of the scalp lesion occurred 72 to 1033 days after incomplete excision. The location on the scalp has not been connected with a high risk of recurrence in the literature [17] and there are not many publications concerning this phenomenon. There is one recent study by Cho et al. [18], in which authors suggest that incomplete excision of scalp BCC is to be connected with a more aggressive growth pattern of the primary lesion, hence the higher recurrence rate. Concerning other locations - such areas as the nose and periorbital region were not connected with a high recurrence risk in our series, although they are in other publications [17]. In our series, BCC of the periorbital region infiltrated the eye only in one case and when located on the nose - it spread onto the nose cartilages only in 2 cases, so the local tissues involvement in most cases was limited in these locations and the amount of tumor tissue left in the skin after incomplete excision - presumably minimal, hence the low recurrence rate.

The most important drawback of our study could be the length of the follow-up period. The recommended follow-up for one patient in order to observe recurrence is 5 years (every 3 months during the first year, then every 6 months) [19]. Some guidelines, like the National Comprehensive Cancer Network guideline in the USA, recommend follow-up every 6-12 months for the whole lifetime [2]. During follow-up control it is necessary to educate the patient on the possibilities of active prophylaxis against BCC, especially regarding sun protection. Moreover, it is also necessary to inform the patient about the need of skin self-examination. It is of special importance not only because of recurrence monitoring, but also due to the risk of development of another BCC, which is ten times higher in patients with a previous BCC than in the general population [13]. This risk is also significantly higher in elderly patients, in patients with multiple BCCs and with the lesion of a diameter $>1 \mathrm{~cm}$ [20]. In some countries general practitioners manage follow-up control after BCC excision [21]. In our department we educate patients after BCC excision in terms of self-control during follow-up appointments in our outpatient clinic. They are informed about clinical symptoms that should raise suspicion of recurrence: scarring with non-healing or recurrent ulceration, a scar that is becoming red, desquamating and looking like ichthyosis, an expanding scar with telangiectasia inside the scar, a nodule appearing within a scar, tissue destruction. In case of any warning signs noticed during self-check at home, patients are instructed to contact one of our physicians in an outpatient setting. We believe that the recurrence rate obtained in our study is accurate and close to reality as patients are referred to our physicians in case of any concerns, despite often not showing up for regular prophylactic follow-up appointments. We also included only patients operated more than 5 years ago, so that the full 5 years' observation and self-examination period could be obtained.

Our results were not classified into groups concerning the surgeon performing operation, what is quite common in other clinical studies where surgical intervention is considered. However, it is not a drawback in our case, as incomplete excision a priori equals an imperfection of the surgical technique and cannot be graded concerning the operating surgeon. All excisions were performed with a standard macroscopic margin of at least $4 \mathrm{~mm}$ and following the same algorithms applied in our department, recommended by the National Comprehensive Cancer 
Network in the USA [2]. However these current algorithms are mostly based on the single report by Wolf of 1987 [22], which is poorly reliable because it did not take into account prognostic factors that have been identified until now. Due to low reliability of studies published so far, the need to perform prospective studies according to evidence-based medicine arises - it is necessary to determine unanimously the range of margins depending on prognostic factors. It is of special importance when BCC is located in functionally and aesthetically important face areas such as the nose (ala nasi, columella, naso-facial sulcus), eyelids, medial and lateral canthus, ear with the preauricular and postauricular region, lips philtrum. All anatomical regions mentioned above are associated with a high risk of recurrence according to literature [17], and the differences in the suggested margin are extremely important. The excision of a lesion with a larger margin may for example result in the removal of lacrimal ducts or cause ectropion. Prospective trials taking into account all factors affecting the range of excision margin, including prognostic factors, would systematize the current state of knowledge and contribute to establishing a consistent algorithm for BCC treatment.

\section{Conclusions}

Based on our experience, observation is an acceptable management option in most patients, as less than a half of incompletely excised BCCS recurred and needed further treatment. A statistically significant higher recurrence rate was observed in lesions characterized by the following factors: location on the scalp, morpheaform histopathological type and recurrent lesion, so they require an especially careful follow-up. Bearing in mind the fact that a split thickness skin graft improves clinical diagnosis of the recurrence, it should be considered as a good option of closure in less prominent locations. As $85 \%$ of recurrences occurred within 3 years after the incomplete excision, clinical observation should be particularly careful during this period, however long-term recurrence should not be underestimated.

\section{Conflict of interest}

The authors declare no conflict of interest.

\section{References}

1. Wong CS, Strange RC, Lear JT. Basal cell carcinoma. BMJ 2003; 327: 794-8.

2. National Comprehensive Cancer Network (NCCN). Clinical Practice Guidelines in Oncology: Basal Cell Skin Cancer V.I.2016.

3. Rubin Al, Chen EH, Ratner D. Basal-cell carcinoma. N Engl J Med 2005; 353: 2262-9.

4. Pascal RR, Hobby LW, Lattes R, Crikelair GF. Prognosis of 'incompletely' versus 'completely excised' basal cell carcinoma. Plast Rec Surg 1968; 41: 328-32.
5. Griffiths RW. Audit of histologically incompletely excised basal cell carcinomas: recommendations for management by re-excision. Br J Plast Surg 1999; 52: 24-8.

6. Kumar P, Orton Cl, McWilliam LJ, Watson S. Incidence of incomplete excision in surgically treated basal cell carcinoma: a retrospective clinical audit. Br J Plast Surg 2000; 53: 563-6.

7. Telfer NR, Colver GB, Morton CA. Guidelines for the management of basal cell carcinoma. Br J Dermatol 2008; 158 : 35-48.

8. Iljin A, Zieliński T, Antoszewski B, Sporny S. Clinicopathological analysis of recurrent basal cell carcinoma of the eyelid. Adv Dermatol Allergol 2016; 33: 42-6.

9. De Silva SP, Dellon AL. Recurrence rate of positive margin basal cell carcinoma: results of a five-year prospective study. J Surg Oncol 1985; 28: 72-4.

10. Wilson AW, Howsam G, Santhanam V, et al. Surgical management of incompletely excised basal cell carcinomas of the head and neck. Br J Oral Maxillofac Surg 2004; 42: 311-4.

11. Bieley HC, Kirsner RS, Reyes BA, Garland LD. The use of Mohs micrographic surgery for determination of residual tumor in incompletely excised basal cell carcinoma. J Am Acad Dermatol 1992; 26: 754-6.

12. Boulinguez S, Grison-Tabone C, Lamant L, et al. Histological evolution of recurrent basal cell carcinoma and therapeutic implications for incompletely excised lesions. Br J Dermatol 2004; 151: 623-6.

13. Marcil I, Stern RS. Risk of developing a subsequent nonmelanoma skin cancer in patients with a history of nonmelanoma skin cancer: a critical review of the literature and metaanalysis. Arch Dermatol 2000; 136: 1524-30.

14. Salasche SJ, Amonette RA. Morpheaform basal-cell epitheliomas. A study of subclinical extensions in a series of 51 cases. J Dermatol Surg Oncol 1981; 7: 387-94.

15. Rowe DE, Carroll RJ, Day CL. Mohs surgery is the treatment of choice for recurrent (previously treated) basal cell carcinoma. J Dermatol Surg Oncol 1989; 15: 424-31.

16. Silverman MK, Kopf AW, Bart RS, et al. Recurrence rates of treated basal cell carcinomas. Part 3: surgical excision. J Dermatol Surg Oncol 1992; 18: 471-6.

17. Wolf DJ, Zitelli JA. Surgical margins for basal cell carcinoma. Arch Dermatol 1987; 123: 340-4.

18. Cho M, Lee J, James CL, et al. Scalp basal cell carcinoma: review of 2,202 cases. Dermatol Surg 2016; 42: 834-41.

19. Liu FF, Maki E, Warde P, et al. A management approach to incompletely excised basal cell carcinomas of skin. Int J Radiat Oncol Biol Phys 1991; 20: 423-8.

20. van lersel CA, van de Velden HV, Kusters CD, et al. Prognostic factors for a subsequent basal cell carcinoma: implications for follow up. Br I Dermatol 2005; 153: 1078-80.

21. Park AJ, Strick M, Watson JD. Basal cell carcinomas: do they need to be followed up? J R Coll Surg Edinb 1994; 39: 109-11.

22. Huang CC, Boyce SM. Surgical margins of excision for basal cell carcinoma and squamous cell carcinoma. Semin Cutan Med Surg 2004; 23: 167-73. 